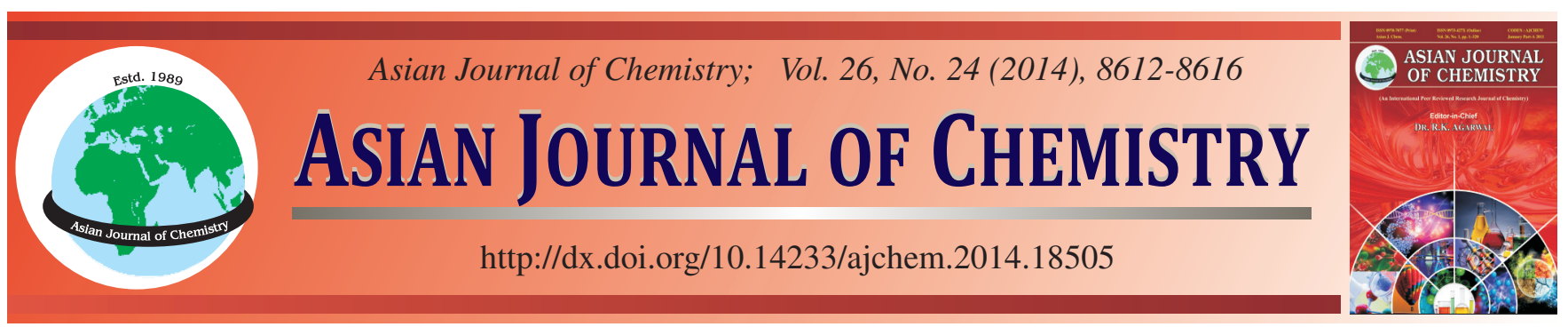

\title{
A Convenient Method to Prepare Novel Alkali Metal Potassium Doped Carbon Nitride Photocatalyst with Tunable Band Structure
}

\author{
Y.F. ZHAO ${ }^{1, *}$, J. ZHANG ${ }^{2}$ and Y.J. WANG ${ }^{2}$
}

${ }^{1}$ School of Environmental and Biological Engineering, Liaoning Shihua University, Fushun 113001, P.R. China

${ }^{2}$ Liaoning Key Laboratory of Petroleum \& Chemical Industry, Liaoning Shihua University, Fushun 113001, P.R. China

*Corresponding author: E-mail: yanfengzhaolnpu@163.com

A novel alkali metal ion $\mathrm{K}^{+}$doped carbon nitride photocatalyst with a tunable band structure was prepared using dicyandiamide monomer and potassium hydrate as precursor. X-ray diffraction, UV-visible, FT-IR and XPS were used to characterize the prepared catalysts. The valence band and conduction band potentials were obviously altered by changing the potassium concentration. Besides, the addition of potassium inhibited the crystal growth of graphitic carbon nitride and increased the separation rate of photogenerated electrons and holes. The visible-light-driven Rhodamine-B photodegradation performance was significantly improved after $\mathrm{K}^{+}$doping. The possible doping site and influence mechanism of potassium concentration on photocatalytic performance was proposed.

Keywords: g- $\mathrm{C}_{3} \mathrm{~N}_{4}$, Potassium doping, Tunable band structure, Visible light.

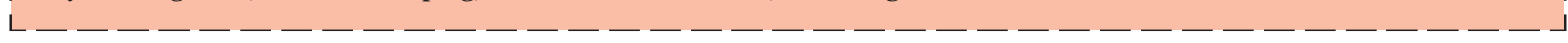

\section{INTRODUCTION}

Nowadays, energy and environmental crisis are the great problems for all the countries in the world. With outstanding virtues, including non-pollution and inexhaustible supply, solar light is considered as one of the most promising candidate to resolve the energy crisis and environmental problems. However, low energy conversion efficiency still restricts its practical application. Recently, a metal-free visible-light photocatalyst graphitic carbon nitride $\left(\mathrm{g}-\mathrm{C}_{3} \mathrm{~N}_{4}\right)$ has attracted intensive interest for its many promising applications. The $\mathrm{g}-\mathrm{C}_{3} \mathrm{~N}_{4}$ has a moderate band gap $(2.7 \mathrm{eV})$, high chemical and thermal stability as well as fascinating electronic property. However, the rapid photogenerated electron-hole pair recombination leads to the low activity in practical applications ${ }^{1,2}$.

Several routes have been developed to solve this problem ${ }^{3-6}$, preparation of porous ${ }^{7} \mathrm{~g}-\mathrm{C}_{3} \mathrm{~N}_{4}$, protonating by strong acids ${ }^{8}$ and designing composite with other semiconductors ${ }^{9}$. Among those strategies, doping is one of the most convenient and effective method. Yan et al. ${ }^{3}$ prepared $\mathrm{B}$ doped $\mathrm{g}-\mathrm{C}_{3} \mathrm{~N}_{4}$ and suggested that the enhanced degradation performance of Rhodamine-B was due to the improvement of dye adsorption and light absorption ability. Zhang et al. $^{4}$ synthesized phosphorus doped $\mathrm{g}-\mathrm{C}_{3} \mathrm{~N}_{4}$ using ionic liquid [Bmim] $\mathrm{PF}_{6}$ as phosphorus source. The obtained material exhibited significantly improved electrical conductivity and photocurrent. Noble metal, such as Pt, Pd and Ag, is an effective dopant to trap the photogenerated electrons, thus improve the separation rate of photogenerated electrons and holes. Bu et al..$^{5}$ prepared Agmodified carbon nitride and found that the separation efficiency was significantly improved, thus enhanced the photoelectric conversion performance. Chang et al. ${ }^{6}$ synthesized $\mathrm{Pd} / \mathrm{mpg}$ $\mathrm{C}_{3} \mathrm{~N}_{4}$ and used for photodegradation of bisphenol A. They found that most of $\mathrm{Pd}$ presented as $\mathrm{Pd}^{0}$ state which acted as electron traps, leading to the improved separation efficiency and photocatalytic performance. However, the high price of noble metal inhibits their practical application.

Because of the active chemical properties, alkali metals are widely used in the catalytic reaction ${ }^{10-12}$. Salinas et al. ${ }^{10}$ prepared potassium-supported $\mathrm{TiO}_{2}$ catalysts for transesterification reaction. Chu et al. ${ }^{11}$ prepared halogen-free $\mathrm{K}^{+}$modified $\mathrm{CuO}_{\mathrm{x}} / \mathrm{SBA}-15$ and used for propylene epoxidation by molecular oxygen. They suggested that $\mathrm{Cu}(\mathrm{I})$ on the surface modified by $\mathrm{K}^{+}$was responsible for the epoxidation. Pekridis et al. ${ }^{12}$ reported the modification effect of $\mathrm{K}^{+}$on $\mathrm{N}_{2} \mathrm{O}$ reduction by alkanes or alkenes over $\mathrm{Pd} / \gamma-\mathrm{Al}_{2} \mathrm{O}_{3}$ catalysts. However, little attention has been given to the investigation of the influence of alkali metal on the promotion of photocatalytic activity ${ }^{13,14}$. Grzechulska et al. ${ }^{13}$ added a series of alkali to crystallized $\mathrm{TiO}_{2}$ slurry to prepare alkali metal modified $\mathrm{TiO}_{2}$ catalysts. The result of photocatalytic decomposition of oil indicated that the activity follows the order: $\mathrm{TiO}_{2} / \mathrm{KOH}>\mathrm{TiO}_{2} / \mathrm{Ca}(\mathrm{OH})_{2}>$ $\mathrm{TiO}_{2} / \mathrm{Ba}(\mathrm{OH})_{2}>\mathrm{TiO}_{2}$ (anatase). Chen et al. prepared $\mathrm{K}^{+}$-doped $\mathrm{TiO}_{2}$ by the sol-gel method and thermal treatment ${ }^{14}$. Calcination 
leads to the formation of $\mathrm{K}_{4-4 \mathrm{x}} \mathrm{Ti}_{\mathrm{x}} \mathrm{O}_{2}$ in which $\mathrm{x}$ value is regarded as promoters of photoactivity. $\mathrm{K}^{+}$doping reduced recombination of the $\mathrm{e}^{-}$and $\mathrm{h}^{+}$pair, enhanced the interfacial charge transfer and improved reactants adsorption on the catalyst. In this work, a novel $\mathrm{K}^{+}$doped carbon nitride photocatalyst with a tunable band structure was prepared for the first time. The photocatalytic activity was evaluated in the photocatalytic degradation of Rhodamine-B under visible light. The effects of doping on the structural property, optical property and photocatalytic performance of as-prepared catalysts were discussed in this work.

\section{EXPERIMENTAL}

In a typical experiment, $2 \mathrm{~g}$ dicyandiamide was dispersed into $10 \mathrm{~mL}$ deionized water under stirring. Then $10 \mathrm{~mL} \mathrm{KOH}$ solution $(0.02,0.05$ and $0.09 \mathrm{M})$ was added. The obtained suspension was heated to $100{ }^{\circ} \mathrm{C}$ to remove the water. The solid product was dried at $80^{\circ} \mathrm{C}$ in oven, followed by milling and annealing at $520{ }^{\circ} \mathrm{C}$ for $2 \mathrm{~h}$ (at a rate of $5^{\circ} \mathrm{C} \mathrm{min}-1$ ). The obtained product was denoted as $\mathrm{CNK}(\mathrm{x})$, where $\mathrm{x}$ stands for the $\mathrm{KOH}$ concentration. When $10 \mathrm{~mL}$ deionized water or $10 \mathrm{~mL} \mathrm{NH}_{4} \mathrm{OH}(0.05 \mathrm{M})$ was used to replace $10 \mathrm{~mL} \mathrm{KOH}$ $(0.05 \mathrm{M})$ following the same procedure as in the synthesis of $\mathrm{CNK}(0.05)$, the product is denoted as neat $\mathrm{g}-\mathrm{C}_{3} \mathrm{~N}_{4}$ or $\mathrm{CNOH}$ (0.05), respectively. For comparison, as-prepared $\mathrm{g}-\mathrm{C}_{3} \mathrm{~N}_{4}$ was dispersed into $10 \mathrm{~mL} \mathrm{KOH}(0.05 \mathrm{M})$. The obtained suspension was stirred for $10 \mathrm{~h}$ and heated to $100{ }^{\circ} \mathrm{C}$ to remove the water. The solid product was dried and denoted as $\mathrm{g}-\mathrm{C}_{3} \mathrm{~N}_{4} / \mathrm{KOH}$.

$\mathrm{X}$-ray diffraction patterns of the prepared samples were recorded on a Rigaku D/max-2400 instrument using $\mathrm{CuK}_{\alpha}$ radiation $(\lambda=1.54 \AA)$. UV-visible spectroscopy measurement was carried out on a JASCO V-550 model UV-visible spectrophotometer, using $\mathrm{BaSO}_{4}$ as the reflectance sample. Fourier transform infrared spectra (FT-IR) were obtained on a Nicolet 20DXB FT-IR spectrometer. ICP was performed to determine the actual K concentration on a Perkin-Elmer Optima 3300DV apparatus. XPS measurements were conducted on a Thermo Escalab 250 XPS system with $\mathrm{Al} \mathrm{K}_{\alpha}$ radiation as the exciting source. The binding energies were calibrated by referencing the $\mathrm{C} 1 \mathrm{~s}$ peak $(284.6 \mathrm{eV})$ to reduce the sample charge effect.

Rhodamine-B was selected as the model compound to evaluate the photocatalytic performance of the prepared $\mathrm{g}-\mathrm{C}_{3} \mathrm{~N}_{4}$ based catalysts in an aqueous solution under visible light irradiation. $0.05 \mathrm{~g}$ catalyst was dispersed in $200 \mathrm{~mL}$ aqueous solution of Rhodamine-B (10 ppm) in an ultrasound generator for $10 \mathrm{~min}$. The suspension was transferred into a self-designed glass reactor and stirred for $0.5 \mathrm{~h}$ in darkness to achieve the adsorption equilibrium. In the photoreaction under visible light irradiation, the suspension was exposed to a $250 \mathrm{~W}$ highpressure sodium lamp with main emission in the range of 400$800 \mathrm{~nm}$ and air was bubbled at $130 \mathrm{~mL} / \mathrm{min}$ through the solution. The UV light portion of sodium lamp was filtered by $0.5 \mathrm{M} \mathrm{NaNO}_{2}$ solution. All runs were conducted at ambient pressure and $30^{\circ} \mathrm{C}$. At given time intervals, $4 \mathrm{~mL}$ suspension was taken and immediately centrifuged to separate the liquid samples from the solid catalyst. The concentrations of Rhodamine-B before and after reaction were measured by UVVisible spectrophotometer at a wavelength of $550 \mathrm{~nm}$.

\section{RESULTS AND DISCUSSION}

Fig. 1 shows the XRD patterns of as-prepared $g-\mathrm{C}_{3} \mathrm{~N}_{4}$ and $\mathrm{CNK}(\mathrm{x})$. The patterns of $\mathrm{g}-\mathrm{C}_{3} \mathrm{~N}_{4}$ and $\mathrm{CNK}(\mathrm{x})$ exhibit two peaks at 13.1 and $27.3^{\circ}$, corresponding to (100) and (002) crystal planes of $\mathrm{g}-\mathrm{C}_{3} \mathrm{~N}_{4}$ (JCPDS 87-1526) ${ }^{15}$. These two peaks show gradually decreased intensity with the increasing potassium concentration, which suggests that the crystal growth of graphitic carbon nitride is inhibited by introduction of potassium. No peak for potassium related species is observed in the pattern of $\operatorname{CNK}(\mathrm{x})$. Whereas, an obvious shift toward a lower $2 \theta$ value is observed for all the $\mathrm{CNK}(\mathrm{x})$ catalysts. This is probably due to that potassium doped into interstitial sites of in-planar $\mathrm{g}-\mathrm{C}_{3} \mathrm{~N}_{4}$ which enlarged the interlayer spacing.

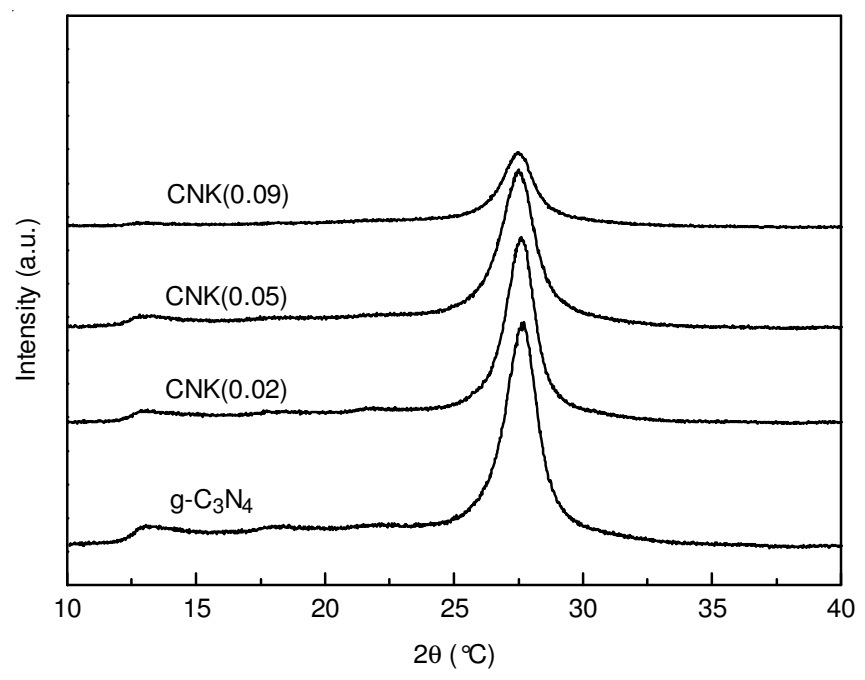

Fig. 1. XRD patterns of as-prepared $\mathrm{g}-\mathrm{C}_{3} \mathrm{~N}_{4}$ and $\mathrm{CNK}(\mathrm{x})$

FT-IR spectra result of as-prepared g- $\mathrm{C}_{3} \mathrm{~N}_{4}$ based catalysts (Fig. 2) shows that the peak at $1640 \mathrm{~cm}^{-1}$ was attributable to C-N stretching vibration modes, while the $1400-1200 \mathrm{~cm}^{-1}$ to aromatic C-N stretching. The band near 3200 and $800 \mathrm{~cm}^{-1}$ are attributed to out-of-plane bending modes of C-N heterocycles and stretching vibration of N-H bond, associated with uncondensed amino groups $^{16}$. For $\mathrm{CNK}(\mathrm{x})$, all the characteristic

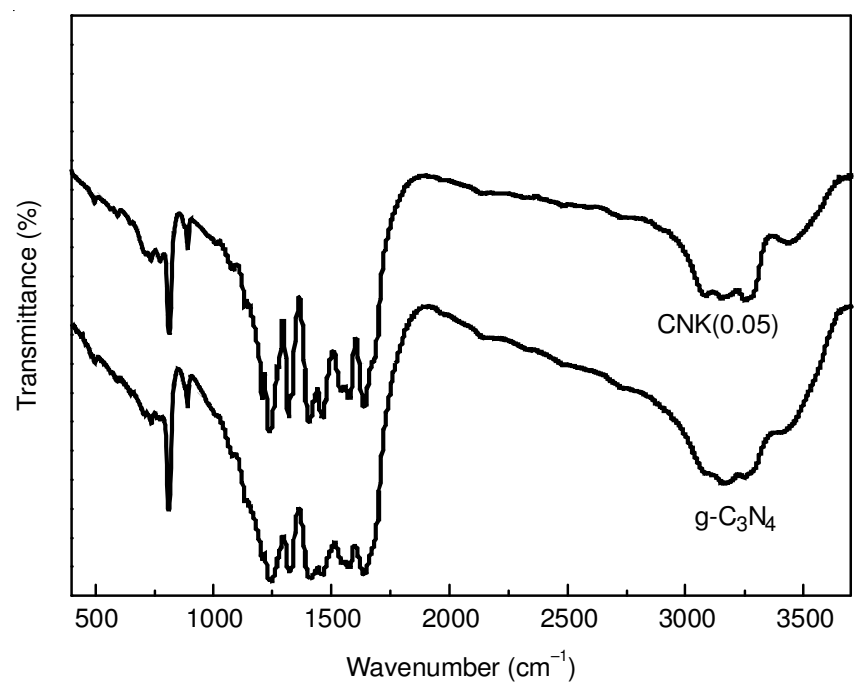

Fig. 2. FT-IR spectra of as-prepared g- $_{3} \mathrm{~N}_{4}$ and $\mathrm{CNK}(0.05)$ 
vibrational peaks of $\mathrm{g}-\mathrm{C}_{3} \mathrm{~N}_{4}$ were observed. The vibrations of $\mathrm{K}$-related group were not observed, suggesting that the framework of $\mathrm{g}-\mathrm{C}_{3} \mathrm{~N}_{4}$ is not changed after $\mathrm{K}$ doping.

The optical absorption of as-prepared $\mathrm{g}-\mathrm{C}_{3} \mathrm{~N}_{4}$ based catalysts was measured using UV-visible diffuse reflectance spectra. As presented in Fig. 3, the main absorption edge of g- $\mathrm{C}_{3} \mathrm{~N}_{4}$ occurs at about $460 \mathrm{~nm}$. The band gap energy of g- $\mathrm{C}_{3} \mathrm{~N}_{4}$ estimated with the Kubelka-Munk function is about $2.65 \mathrm{eV}$, which is in good agreement with the value reported in previous literature $^{17}$. In the case of $\mathrm{CNK}(\mathrm{x})$, the obvious red shifts of the absorption band are observed. However, no obvious difference between $\mathrm{g}-\mathrm{C}_{3} \mathrm{~N}_{4}$ and $\mathrm{g}-\mathrm{C}_{3} \mathrm{~N}_{4} / \mathrm{KOH}$ was shown. This suggests that the existence form of potassium species in $\mathrm{g}-\mathrm{C}_{3} \mathrm{~N}_{4} / \mathrm{KOH}$ and $\mathrm{CNK}(\mathrm{x})$ is different. The band gap energy decreased to 2.6, 2.57 and $2.52 \mathrm{eV}$ for CNK (0.02), CNK (0.05) and CNK (0.09). This indicated that potassium concentration strongly influences the optical property and band structure of as-prepared g- $\mathrm{C}_{3} \mathrm{~N}_{4}$ based catalysts. Ma et al. ${ }^{18}$ calculated the electronic structure of phosphorus doped $\mathrm{g}-\mathrm{C}_{3} \mathrm{~N}_{4}$ using first-principles. They found that isolated P $3 p$ orbital was localized below the bottom of the conduction band in the host $\mathrm{g}-\mathrm{C}_{3} \mathrm{~N}_{4}$, thus decreased the band gap energy. Similarly, after potassium doping, an isolated atomic orbital of dopant may locate in the $\mathrm{g}-\mathrm{C}_{3} \mathrm{~N}_{4}$ band gap, or orbital hybridization occurs between dopant orbital and molecular orbital of $\mathrm{g}-\mathrm{C}_{3} \mathrm{~N}_{4}$, leading to the altered position of valence band and conduction band.

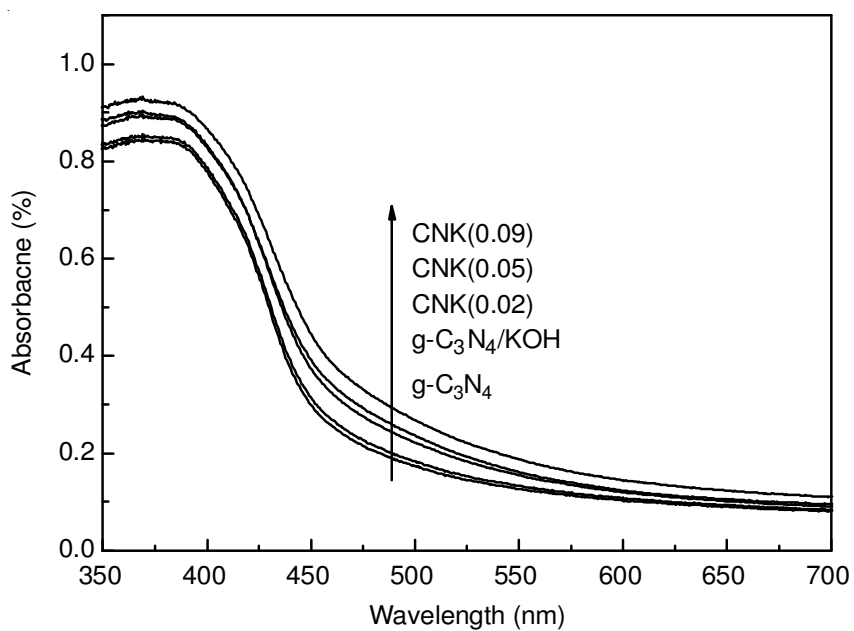

Fig. 3. UV-visible diffuse reflectance spectra of as-prepared $\mathrm{g}-\mathrm{C}_{3} \mathrm{~N}_{4}$ based catalysts

X-ray photoelectron spectroscopy (XPS) measurements were performed to explicate the valence states of various species. Fig. 4 displays the XP spectra of as-prepared $g-\mathrm{C}_{3} \mathrm{~N}_{4}$ based catalysts in the region of K $2 p$ (a) and valence band XPS (b). As shown in Fig. 4a, the binding energy of $g-\mathrm{C}_{3} \mathrm{~N}_{4} / \mathrm{KOH}$ in $\mathrm{K}$ $2 \mathrm{p}$ region was located at $292.7 \mathrm{eV}$, which should be attributed to the K-O group ${ }^{19}$. In the case of CNK (0.05), a obvious shift to lower binding energy $(0.2 \mathrm{eV})$ was observed. Besides, the calculation result of surface elemental concentration determined by XPS reveals that K concentration in CNK (0.05) was 1.46 wt. $\%$, which is close to the ICP result ( $1.35 \mathrm{wt} . \%)$. In the case of $\mathrm{g}-\mathrm{C}_{3} \mathrm{~N}_{4} / \mathrm{KOH}$, this value is $3.3 \mathrm{wt}$. $\%$, much higher than that of ICP result (1.39 wt. \%). This is probably due to the different existence form of $\mathrm{K}$ species in two samples. For g- $\mathrm{C}_{3} \mathrm{~N}_{4} / \mathrm{KOH}$,
$\mathrm{K}$ species mainly exists on the surface. Whereas $\mathrm{K}$ could be doped into g- $\mathrm{C}_{3} \mathrm{~N}_{4}$ lattice in the formation of $\mathrm{K}-\mathrm{N}$ bond during the polycondensation process, leading to the uniform dispersion in the bulk of CNK (0.05). Moreover, K doping could influence the chemical environments of both $\mathrm{N}$ and $\mathrm{K}$ atoms. The lone electron pair of nitrogen causes the electron-rich structure of g- $\mathrm{C}_{3} \mathrm{~N}_{4}$. Therefore, $\mathrm{K}$ could be coordinated to $\mathrm{N}$ ligands and stabilized by the lone electron pair. The similar structure such as Fe doped $\mathrm{g}_{-} \mathrm{C}_{3} \mathrm{~N}_{4}$ has been reported ${ }^{20}$. Thus, the electron density increased for $\mathrm{K}$ atoms, leading to the binding energy shifts (Fig. 4a). It is known that the lone pair electron of nitrogen plays an important role in the electronic structure of carbon nitride ${ }^{21}$. The doping of $\mathrm{K}$ could influence the electron density of $\mathrm{N}$ atoms, thus altered the electronic structure and band gap of carbon nitride. As for the doping site of potassium, the probably situation is interstitial sites. The ionic radius of $\mathrm{K}$ is much larger than that of $\mathrm{C}$ and $\mathrm{N}$, the substitutional doping should not occur. Besides, the maximum in-planar distance of nitride pores is $0.71 \mathrm{~nm}^{22}$, which is adequate to accommodate the K ions. Summarizing the above results, the possible doping site of $\mathrm{K}$ ions in $\mathrm{CNK}(\mathrm{x})$ is as shown in Fig. 5.

To further investigate the influence of $\mathrm{K}$ doping on the relative positions of the conduction band and valence band, the valence band XP spectra was employed to determine the
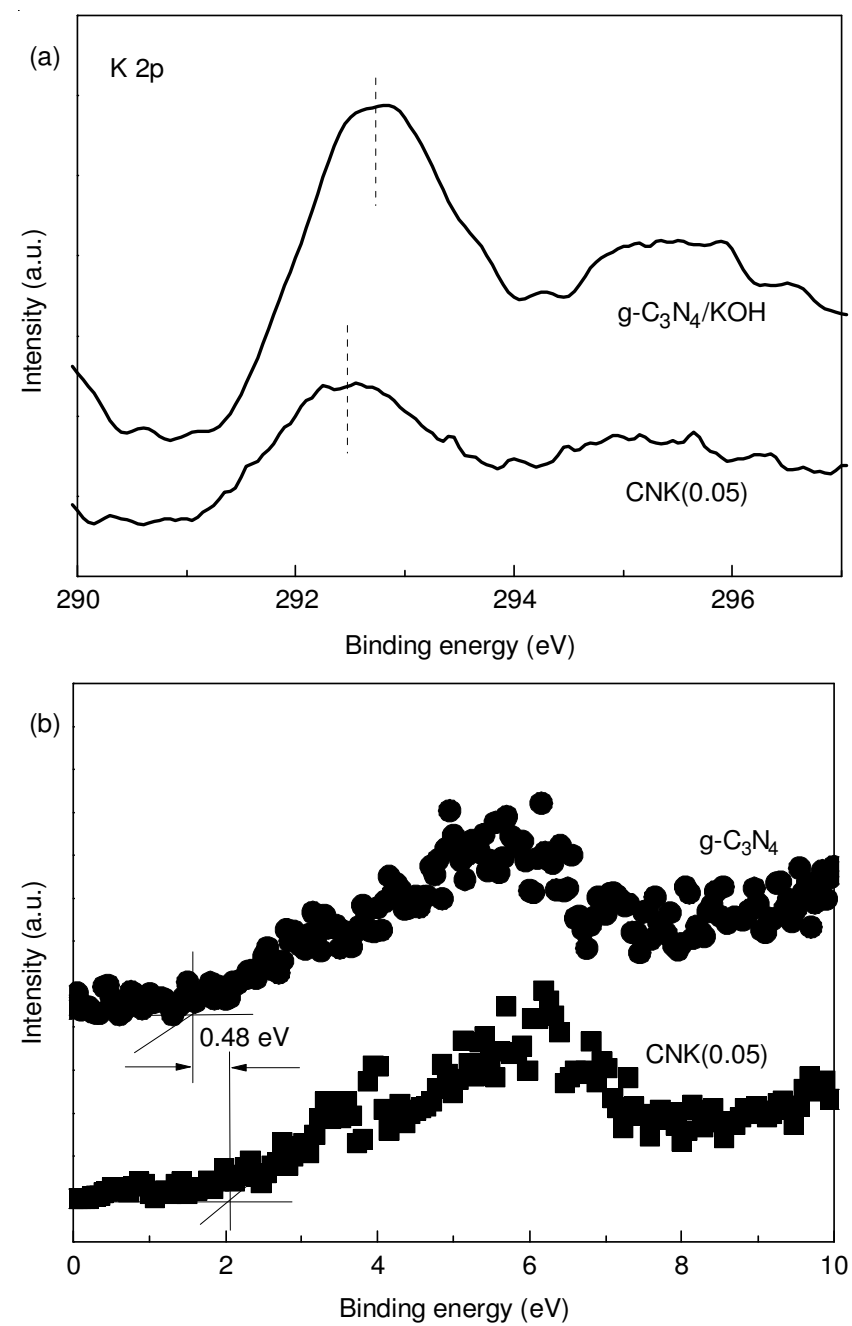

Fig. 4. XP spectra of as-prepared $\mathrm{g}-\mathrm{C}_{3} \mathrm{~N}_{4}$ based catalysts in the region of $\mathrm{K}$ $2 \mathrm{p}$ (a) and valence band XPS (b) 


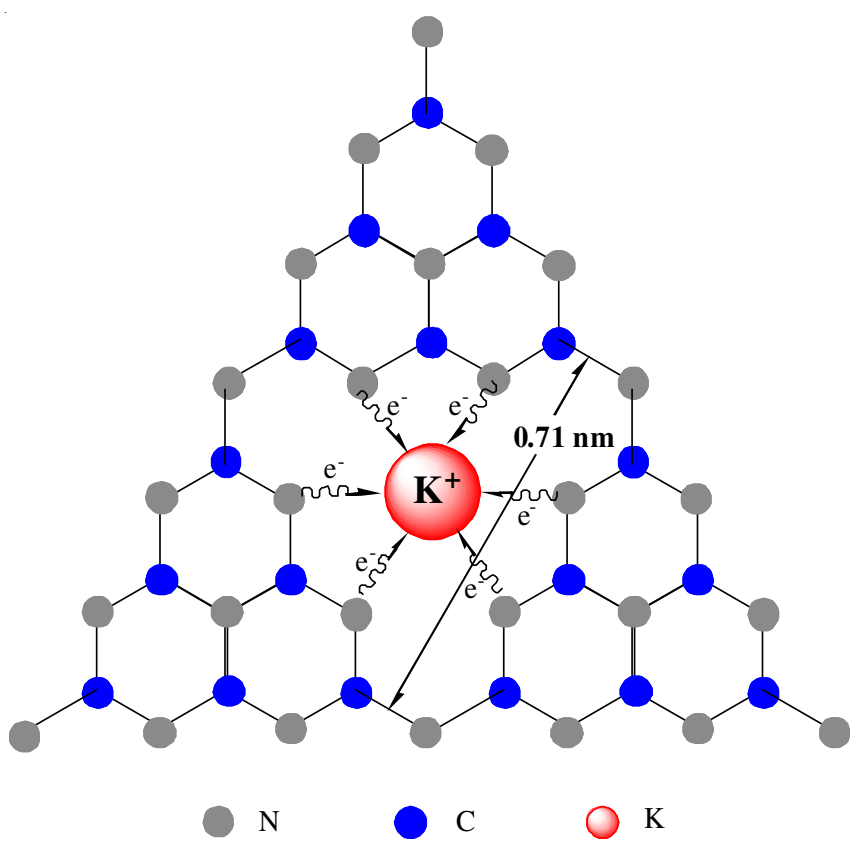

Fig. 5. Possible doping site of $\mathrm{K}$ ions in $\mathrm{CNK}(\mathrm{x})$

electronic structure (Fig. 4b). Compared with the spectrum of g- $\mathrm{C}_{3} \mathrm{~N}_{4}$, an obvious shift $(0.48 \mathrm{eV})$ is shown in $\mathrm{CNK}(0.05)$, which should be attributed to the $\mathrm{K}$ atoms doped into $\mathrm{g}-\mathrm{C}_{3} \mathrm{~N}_{4}$ lattice. The valence band of $\mathrm{g}_{-} \mathrm{C}_{3} \mathrm{~N}_{4}$ and $\mathrm{CNK}(0.05)$ locate at +1.56 and $+2.04 \mathrm{eV}$, respectively. Combined with the UV-visible result, the optical conduction band potentials of $\mathrm{g}-\mathrm{C}_{3} \mathrm{~N}_{4}$ and $\mathrm{CNK}(0.05)$ locate at -1.09 and $-0.53 \mathrm{eV}$, respectively. The valence band and conduction band potentials of other $\mathrm{K}$ doped $\mathrm{g}-\mathrm{C}_{3} \mathrm{~N}_{4}$ catalysts were calculated and shown in Fig. 6. Obviously, the conduction band and valence band positions were obviously altered with increasing the potassium concentration. The conduction band and valence band potentials could be tuned from -1.09 and +1.56 $\mathrm{eV}$ to -0.31 and $+2.21 \mathrm{eV}$, respectively by controlling the $\mathrm{K}$ concentration. Such tunable conduction band and valence band potentials are beneficial to form the heterojunction with other semiconductors to meet different application demands.

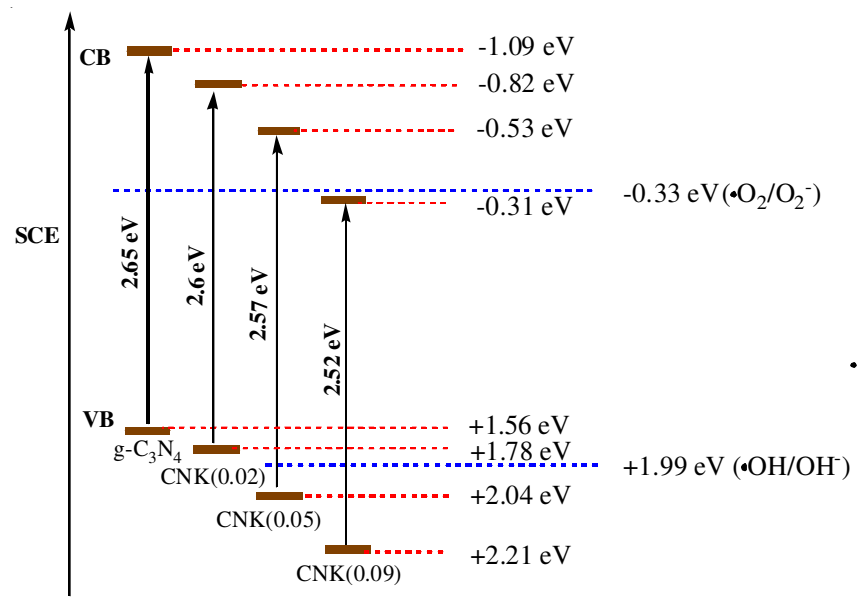

Fig. 6. Band gap structures of as-prepared $g-\mathrm{C}_{3} \mathrm{~N}_{4}$ and $\mathrm{CNK}(\mathrm{x})$

Fig. 7a shows the photocatalytic performances of as-prepared g- $\mathrm{C}_{3} \mathrm{~N}_{4}$ based catalysts in the degradation of Rhodamine- $\mathrm{B}$ under visible light irradiation. $\mathrm{CNK}(\mathrm{x})$ catalysts show clearly higher activity than that of $\mathrm{g}-\mathrm{C}_{3} \mathrm{~N}_{4}$. Whereas, as shown in Fig. 8 , g- $\mathrm{C}_{3} \mathrm{~N}_{4} / \mathrm{KOH}$ and $\mathrm{CNOH}(0.05)$ exhibit almost the same photocatalytic activities as $\mathrm{g}-\mathrm{C}_{3} \mathrm{~N}_{4}$. This hints two points. First of all, the existence form of potassium species in $\mathrm{g}-\mathrm{C}_{3} \mathrm{~N}_{4} / \mathrm{KOH}$ and $\mathrm{CNK}(\mathrm{x})$ is different, which is consistent with $\mathrm{UV}$-visible result. Secondly, the improved activity is not attributed by the alkali treatment but by the $\mathrm{K}$ doping. The photocatalytic activity enhanced gradually with increasing the $\mathrm{K}$ concentration from 0.02 to 0.05 . CNK (0.05) showed much higher photocatalytic activity than that of other potassium doped catalysts. When the K concentration beyond 0.05 , the activity decreased remarkably. The reaction rate constant $\mathrm{k}$ was obtained by assuming that the reaction followed first order kinetics ${ }^{23}$. Fig. $7 \mathrm{~b}$ displays that a linear relationship is established when $-\ln \left(C / C_{0}\right)$ is plotted against $\mathrm{t}$ (reaction time). The rate constant $\mathrm{k}$ can be calculated by the slope of the line. The results indicated that the rate constant $\mathrm{k}$ were $0.0017,0.0074,0.011$ and 0.0037 $\mathrm{min}^{-1}$ for $\mathrm{g}-\mathrm{C}_{3} \mathrm{~N}_{4}, \mathrm{CNK}$ (0.02), CNK (0.05) and CNK (0.09). $\mathrm{CNK}(0.05)$ shows the highest rate constant, which is 6.4 times higher than that of $\mathrm{g}-\mathrm{C}_{3} \mathrm{~N}_{4}$.

\section{Conclusion}

A novel alkali metal potassium doped carbon nitride photocatalyst with a tunable band structure was prepared using dicyandiamide monomer and potassium hydrate as precursor. Potassium doped $\mathrm{g}-\mathrm{C}_{3} \mathrm{~N}_{4}$ exhibited smaller grain size and
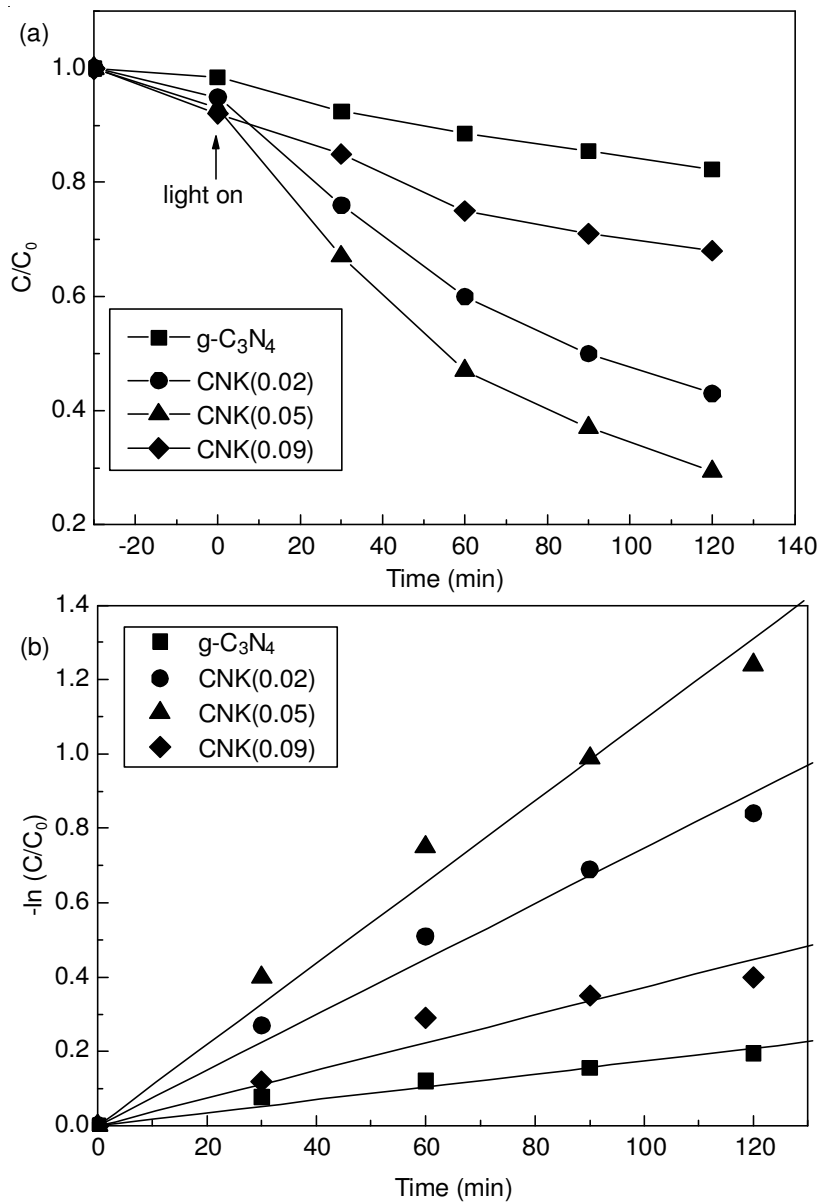

Fig. 7. Photocatalytic performances of as-prepared $\mathrm{g}-\mathrm{C}_{3} \mathrm{~N}_{4}$ based catalysts (a) and plot of $-\ln \left(\mathrm{C} / \mathrm{C}_{0}\right)$ against reaction time (b) in the degradation of Rhodamine-B under visible light irradiation 


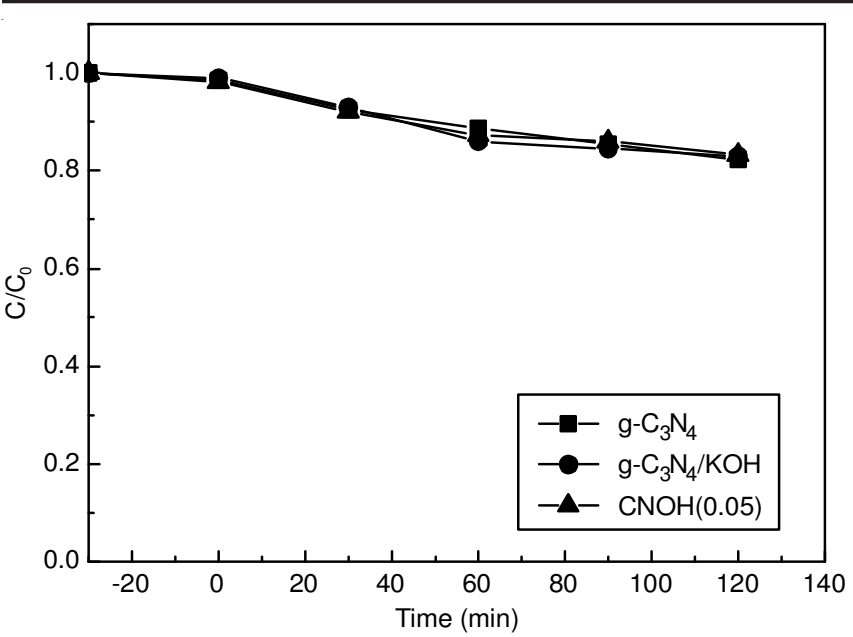

Fig. 8. Photocatalytic performances comparison of as-prepared $\mathrm{g}-\mathrm{C}_{3} \mathrm{~N}_{4}$, g- $\mathrm{C}_{3} \mathrm{~N}_{4} / \mathrm{KOH}$ and $\mathrm{CNOH}(0.05)$

narrower band gap energy. The contrast experiment results indicated that those changes are not caused by the alkalization treatment but by potassium doping. The conduction band and valence band potentials of as-prepared $\mathrm{CNK}(\mathrm{x})$ were obviously altered by changing the potassium concentration. Potassium could be coordinated to $\mathrm{N}$ ligands, stabilized by the lone electron pair and doped in interstitial sites. The photodegradation performance of Rhodamine-B was significantly improved after potassium doping under visible light. The improved activity is not attributed by the alkali treatment but by the $\mathrm{K}$ doping. CNK (0.05) shows the highest rate constant, which is 6.4 times higher than that of $\mathrm{g}-\mathrm{C}_{3} \mathrm{~N}_{4}$.

\section{REFERENCES}

1. K. Sridharan, E. Jang and T.J. Park, Appl. Catal. B, 142-143, 718 (2013).

2. P. Niu, L. Zhang, G. Liu and H. Cheng, Adv. Funct. Mater., 22, 4763 (2012).
3. S.C. Yan, Z.S. Li and Z.G. Zou, Langmuir, 26, 3894 (2010).

4. Y.J. Zhang, T. Mori, J.H. Ye and M. Antonietti, J. Am. Chem. Soc., 132, 6294 (2010).

5. Y.Y. Bu, Z.Y. Chen and W.B. Li, Appl. Catal. B, 144, 622 (2014).

6. C. Chang, Y. Fu, M. Hu, C.Y. Wang, G.Q. Shan and L.Y. Zhu, Appl. Catal. B, 142-143, 553 (2013).

7. F. Goettmann, A. Fischer, M. Antonietti and A. Thomas, Angew. Chem. Int. Ed., 45, 4467 (2006).

8. Y.J. Zhang, A. Thomas, M. Antonietti and X.C. Wang, J. Am. Chem. Soc., 131, 50 (2009).

9. C.S. Pan, J. Xu, Y.J. Wang, D. Li and Y.F. Zhu, Adv. Funct. Mater., 22, 1518 (2012).

10. D. Salinas, P. Araya and S. Guerrero, Appl. Catal. B, 117-118, 260 (2012).

11. H. Chu, L.J. Yang, Q.H. Zhang and Y. Wang, J. Catal., 241, 225 (2006).

12. G. Pekridis, N. Kaklidis, M. Konsolakis, C. Athanasiou, I.V. Yentekakis and G.E. Marnellos, Solid State Ion., 192, 653 (2011).

13. J. Grzechulska, M. Hamerski and A.W. Morawski, Water Res., 34, 1638 (2000).

14. L.C. Chen, C.-M. Huang and F.-R. Tsai, J. Mol. Catal. Chem., 265, 133 (2007).

15. Y. Wang, X.C. Wang and M. Antonietti, Angew. Chem. Int. Ed., 51, 68 (2012)

16. S.C. Yan, Z.S. Li and Z.G. Zou, Langmuir, 25, 10397 (2009).

17. G.Q. Li, N. Yang, W.L. Wang and W.F. Zhang, J. Phys. Chem. C, 113, 14829 (2009).

18. X.G. Ma, Y.H. Lv, J. Xu, Y.F. Liu, R.Q. Zhang and Y.F. Zhu, J. Phys. Chem. C, 116, 23485 (2012).

19. A. Miyakoshi, A. Ueno and M. Ichikawa, Appl. Catal. A Gen., 219, 249 (2001).

20. S.Z. Hu, R.R. Jin, G. Lu, D. Liu and J.Z. Gui, RSC Adv., 4, 24863 (2014).

21. G.P. Dong, Y.H. Zhang, Q.W. Pan and J.R. Qiu, J. Photochem. Photobiol. Photochem. Rev., 20, 33 (2014).

22. X.G. Ma, Y.H. Lv, J. Xu, Y.F. Liu, R.Q. Zhang and Y.F. Zhu, J. Phys. Chem. C, 116, 23485 (2012).

23. X.Y. Li, D.S. Wang, G.X. Cheng, Q.Z. Luo, J. An and Y.H. Wang, Appl. Catal. B, 81, 267 (2008). 